Abstract

\title{
A Retrospective and Cross-Sectional Study to Evaluate the Effect of Acculturation on the Dietary Calcium Intake and Predictors of Bone Mineral Density in Filipino Women Recently Immigrated to New Zealand ${ }^{\dagger}$
}

\author{
Rosario Monzales ${ }^{1}$, M.C. Kruger ${ }^{2}$, B. Burlingame ${ }^{3}$, L. Norrish ${ }^{1}$ and P.R. von Hurst ${ }^{1, *}$ \\ 1 School of Sport, Exercise and Nutrition, College of Health, Massey University, Auckland 0632, \\ New Zealand; riomonzales@gmail.com (R.M.); ltnorrish@gmail.com (L.N.) \\ 2 School of Health Science, College of Health, Massey University, Palmerston North 4474, New Zealand; \\ M.C.Kruger@massey.ac.nz \\ 3 School of Health Sciences, College of Health, Massey University, Wellington 6021, New Zealand; \\ b.burlingame@massey.ac.nz \\ * Correspondence:p.r.vonhurst@massey.ac.nz \\ + Presented at the 2018 Nutrition Society of New Zealand Annual Conference, Auckland, New Zealand, \\ 28-30 November 2018.
}

Published: 12 March 2019

Background: Filipinos in New Zealand have steadily grown in number over recent decades, and the majority undergo a dietary acculturation process, which is the dietary adaptation of individuals in their host country. In the Philippines, the nutrient with the highest inadequacy in the diet is calcium, which is primarily contributed by fish and indigenous vegetables that are not readily available in New Zealand. The aim of this study was to determine the effect of dietary acculturation on the calcium intake of Filipino women recently immigrated to New Zealand, and to explore the primary factors affecting their bone mineral status.

Methods: Current and previous dietary calcium intake, serum $25(\mathrm{OH}) \mathrm{D}$, physical activity data from accelerometers, and bone mineral density (BMD) and body composition from dual-energy Xray absorptiometry (DXA) were measured. Gross lean mass was calculated (total mass - [whole body total bone content + total fat mass]). The variables considered to be associated with bone mineral status were applied to a multiple regression analysis using the enter method.

Results: Healthy pre-menopausal Filipino women ( $\mathrm{N}=62,20-45$ years old) were recruited. Their median calcium intake in New Zealand following immigration $[418(260,620) \mathrm{mg} / \mathrm{d}]$, was significantly lower $(p=0.02)$ than the intake in the Philippines $[506(358,823) \mathrm{mg} / \mathrm{d}]$. Mean T-scores total hip $(-0.82 \pm 0.94)$ and lumbar spine $(-0.82 \pm 0.95)$ were within normal range $(-1.0-1.0)$. The significant predictor of BMD was gross lean mass, whereas current and previous dietary calcium intake, physical activity and serum $25(\mathrm{OH}) \mathrm{D}$ were not significant predictors. However, a high prevalence $(69 \%)$ of serum $25(\mathrm{OH}) \mathrm{D}<50 \mathrm{nmol} / \mathrm{L}$ (mild-moderate deficiency) was detected.

Conclusions: These findings illustrate the potential detrimental consequences of dietary acculturation on the essential nutrient intake of immigrants, but also provide an opportunity to correct previous dietary inadequacies by exposing the participants to corresponding nutrient-dense foods from the host country. 
Supplementary Material: The poster is available online at www.mdpi.com/2504-3900/8/1/44/s1. article distributed under the terms and conditions of the Creative Commons Attribution (CC BY) license (http://creativecommons.org/licenses/by/4.0/). 